\title{
AVALIAÇÃO DA INFLUÊNCIA DA UTILIZAÇÃO DO PÓ DE VIDRO ÂMBAR COMO AGREGADO MIÚDO NAS PROPRIEDADES DO CONCRETO
}

\author{
J.P.N. BARBOSA \\ Engenheiro Civil \\ CEULP/ULBRA \\ Tocantins; Brasil \\ jpnoletobarbosa@gmail.com
}

\author{
J. SOUSA \\ Engenheiro Civil \\ IFTO \\ Tocantins; Brasil \\ jamesdesousa0@gmail.com
}

\author{
D.H.B. SILVA \\ Engenheiro Civil \\ CEULP/ULBRA \\ Tocantins; Brasil \\ diego.heiner.eng@gmail.com
}

\author{
F.H.M. RIBEIRO \\ Engenheiro Civil \\ CEULP/ULBRA \\ Tocantins; Brasil \\ fabioribeiro@ceulp.edu.br
}

\section{RESUMO}

O concreto é um dos materiais de construção mais utilizados no mundo. Nos últimos anos, tem havido um grande interesse na utilização de resíduos de materiais e subprodutos em concretos. O uso desses materiais não só reduz o custo da fabricação do concreto, como também oferece vários benefícios ecológicos, como reduzir o custo do aterro sanitário, poupar energia e proteger o meio ambiente das possíveis poluições. Além disso, a sua utilização pode melhorar as propriedades de microestrutura, mecânica e durabilidade da argamassa e concreto. Este trabalho objetivou analisar a viabilidade técnica e do concreto com o uso do pó de vidro âmbar como substituição parcial do agregado miúdo do concreto convencional. Adotando como teores de substituição do agregado miúdo pelo resíduo, $10 \%, 20 \%$ e $40 \%$ (referentes à massa peso de cimento). O resíduo foi oriundo de garrafas "long neck", por não ser um recipiente retornável e não haver coleta seletiva na cidade de Palmas - TO. As substituições provocaram um aumento no abatimento devido a menor absorção do vidro e sua forma menos angular do que a da areia natural. No que se refere à resistência, a medida que se aumentou o teor de vidro, perdeu-se resistência, porém torna-se viável substituições de até $20 \%$ por ter alcançado uma resistência dentro do fck da dosagem (27,2 MPa).

Palavras-chave: Concreto, Sustentabilidade, Vidro Ambar.

\begin{abstract}
Concrete is one of the most widely used building materials in the world. In recent years, there has been a great deal of interest in the use of waste materials and by-products in concrete. The use of these materials not only reduces the cost of concrete manufacturing, but also offers a number of ecological benefits, such as reducing the cost of landfill, saving energy and protecting the environment from potential pollution. In addition, their use can improve the microstructure, mechanical and durability properties of mortar and concrete. This work aimed to analyze the technical and concrete viability with the use of the amber glass powder as partial replacement of the small aggregate of conventional concrete. Adopting as substitute contents of the small aggregate by the residue, 10\%, 20\% and 40\% (referring to the mass weight of cement). The residue was from long neck bottles, because it was not a returnable container and there was no selective collection in the city of Palmas - TO. The substitutions caused an increase in the abatement due to the lower absorption of the glass and its less angular form than the natural sand. As regards strength, as glass content has been increased, resistance has been lost, but substitutions of up to $20 \%$ have become feasible because they have achieved a resistance within the dosage fck (27.2 MPa).
\end{abstract}

Keywords: Concrete, sustainability, Ambar Glass. 


\section{INTRODUÇÃO}

Em virtude da larga utilização do concreto, surgiu um grande interesse na utilização de resíduos de materiais e subprodutos como agregados para concretos. O uso desses materiais não só reduz o custo da fabricação do concreto, como também oferece vários benefícios ecológicos, como reduzir o custo do aterro sanitário, poupar energia e proteger o meio ambiente das possíveis poluições. Além disso, a sua utilização pode melhorar as propriedades de microestrutura, mecânica e durabilidade da argamassa e concreto. (GOUVEIA, 2012). Dentre os diversos resíduos gerados, o vidro assume um papel relevante, uma vez que o Brasil produz em média 980 mil toneladas por ano, dos quais apenas aproximadamente 441 mil toneladas (45\%) são alvo de processos de reaproveitamento. O principal mercado para reciclagem de vidros é formado pelas vidrarias, que compram o material de sucateiros na forma de cacos ou recebem diretamente de suas campanhas de reciclagem (CEMPRE, 2018). Alia-se a essa larga geração de resíduos de vidro o fato de ser um material composto basicamente por sílica e apresenta alta resistência à ruptura. O vidro é um material cerâmico, sólido não cristalino de óxido tradicional. Entre as principais características do vidro destaca-se sua elevada durabilidade química (SHACKELFORD, 2008). O uso de vidro no concreto já foi amplamente estudado e alguns países já utilizam este material como agregado fino no concreto, a Austrália, por exemplo, utiliza o vidro moído proveniente do lixo em concretos para construção civil. No Brasil, esta forma de valorização desse recurso é pouco utilizada, uma vez que o aterro é uma opção muito barata e a disponibilidade de matéria-prima para materiais de construção ainda é abundante (LOPEZ; AZEVEDO; NETO, 2005). Sendo assim, tornou-se relevante analisar a influência desse material nas propriedades do concreto convencional, no estado fresco e endurecido, substituindo o agregado miúdo por ele, para que, de posse de um teor ótimo de substituição, se pudesse chegar a um concreto mais ecológico e econômico.

\section{O PÓ DE VIDRO COMO AGREGADO MIÚDO NO CONCRETO}

Segundo Taha e Nounu (2009), a utilização do resíduo de vidro na substituição do agregado miúdo em concretos possui alto risco de ocorrência da reação álcali-sílica (RAS), o que pode gerar fissuras e danos à durabilidade dos concretos. Os autores concluíram que para evitar a ocorrência de RAS deverá ser utilizado algum supressor desse tipo de reação, tais como escória de alto forno, metacaulim, pó de vidro pozolânico e nitrato de lítio. Shi e Zeng, (2007), asseguram que para diminuir a expansão devido a RAS podem ser utilizados adições minerais principalmente em cimento pozolânico. Diversos autores sugerem também que o tamanho das partículas pode influenciar diretamente no aparecimento da reação álcali-sílica, prejudicando fortemente a durabilidade das estruturas de concreto. Ismail e Al-Hashmi (2009), afirma que as expansões devido a RAS são controladas quando o resíduo de vidro utilizado apresenta uma granulometria fina. Silva (2015) apud Lee (2003) relata que o vidro comum apresenta baixo coeficiente de expansão térmico e contém baixo teor de álcalis, sendo pouco reativo, portanto pode-se descartar a possibilidade de formação de gel expansivo, não comprometendo a durabilidade do concreto nesse quesito. $\mathrm{O}$ uso de materiais reciclados agregados ao concreto já foi amplamente estudado. López, Azevedo e Neto (2005), por exemplo, pesquisaram o uso de vidro reciclado como substituto do agregado miúdo no concreto. Alguns destes materiais são adicionados com o intuito de melhorar as características mecânicas dos concretos ou simplesmente são adicionados para diminuir a quantidade de materiais destinados aos aterros. O uso de vidro já foi estudado e alguns países já utilizam este material como agregado fino no concreto, a Austrália, por exemplo, utiliza o vidro moído proveniente do lixo em concretos para construção. No Brasil, esta forma de valorização desse recurso é pouco utilizada, uma vez que o aterro é uma opção muito barata e a disponibilidade de matéria-prima para materiais de construção é abundante (LOPEZ; AZEVEDO; NETO, 2005).

\section{MATERIAIS E MÉTODOS}

\subsection{Cimento}

O cimento utilizado para a composição foi o CP-II-Z-32. Este cimento, com adição de pozolana, ideal para situações de potenciais ataques químicos.

A Tabela 1 apresenta valores médios das características físicas e químicas desse cimento, relevantes para este estudo segundo o fabricante. 
Tabela 1 - Características físicas e químicas do cimento CP-II-Z-32 ( Itambé Cimentos, 2019: disponível em $<$ https://www.cimentoitambe.com.br/relatorios-de-ensaio >)

\begin{tabular}{l|c}
\hline \multicolumn{1}{c}{ Características do Cimento CP-II-Z-32 } \\
\hline Finura na peneira \# 200 (NBR 11579:2023) & $1,53 \%$ \\
\hline Resistência à compressão (NBR 7215:2019) & $41,0 \mathrm{MPa}$ \\
\hline Resíduo insolúvel (NBR NM 15:2012) & $11,05 \%$ \\
\hline Óxido de alumínio (NBR 14656:2001) & $7,35 \%$ \\
\hline Óxido de silício (NBR 14656:2001) & $20,83 \%$ \\
\hline Óxido de cálcio (NBR 14656:2001) & $54,56 \%$ \\
\hline Óxido de ferro (NBR 14656:2001) & $3,25 \%$ \\
\hline Óxido de magnésio (NBR 14656:2001) & $2,53 \%$ \\
\hline Óxido de enxofre (NBR 14656:2001) & $2,60 \%$ \\
\hline Óxido de cálcio livre (NBR NM 15:2012) & $0,79 \%$ \\
\hline
\end{tabular}

\subsection{Agregado Miúdo}

Os agregados miúdos foram empregados tanto a areia média, que é proveniente da região de Palmas/TO.

Tabela 1 - Ensaios de caracterizados os agregado miúdo (Autor, 2019)

\begin{tabular}{l|c}
\hline \multicolumn{2}{c}{ Caracterização dos agregados } \\
\hline Massa unitária do agregado miúdo (NBR NM 45:2006) & $1,569 \mathrm{~g} / \mathrm{cm}^{3}$ \\
\hline Massa específica do agregado miúdo (NBR NM53:2009) & $2,630 \mathrm{~g} / \mathrm{cm}^{3}$ \\
\hline Teor de material pulverulento (NBR NM 46:2003) & $0,88 \%$ \\
\hline Módulo de finura da areia (NBR NM- 248:2003) & 2,55 \\
\hline Dimensão máxima característica (NBR NM- 248:2003) & $4,8 \mathrm{~mm}$ \\
\hline
\end{tabular}

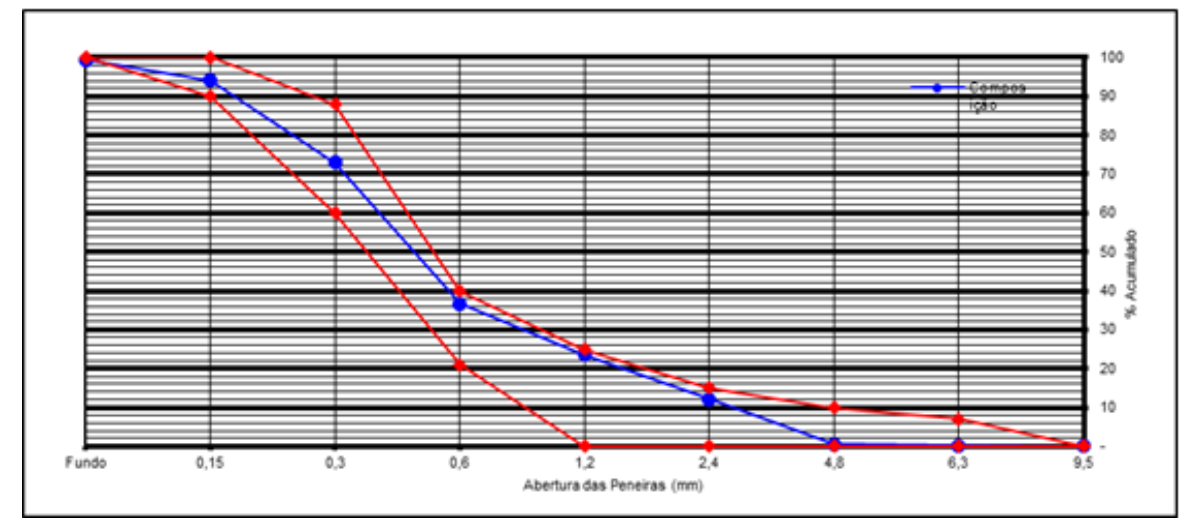

Figura 1 Composição granulométrica do agregado miúdo (Autor, 2019)

A Figura 1 apresenta as curvas granulométricas dos agregados miúdos estudados, as cores vermelhas representam o limite inferior e superior da zona utilizável, na cor azul é a curva granulométrica da zona ótima de utilização.

\subsection{Agregado Graúdo}

O agregado graúdo utilizado foi a brita 1 de origem granítica e proveniente da região de Palmas/TO.

Tabela 2 - Ensaios de caracterizados os agregado miúdo (Autor, 2019)

Caracterização dos agregados

\begin{tabular}{l|c}
\multicolumn{2}{c}{ Caracterização dos agregados } \\
\hline Massa unitária do agregado miúdo (NBR NM 45:2006) & $1,622 \mathrm{~g} / \mathrm{cm}^{3}$ \\
\hline Massa específica do agregado miúdo (NBR NM53:2009) & $2,664 \mathrm{~g} / \mathrm{cm}^{3}$ \\
\hline Módulo de finura da areia (NBR NM- 248:2003) & 6,05 \\
\hline Dimensão máxima característica (NBR NM- 248:2003) & $19,0 \mathrm{~mm}$ \\
\hline
\end{tabular}




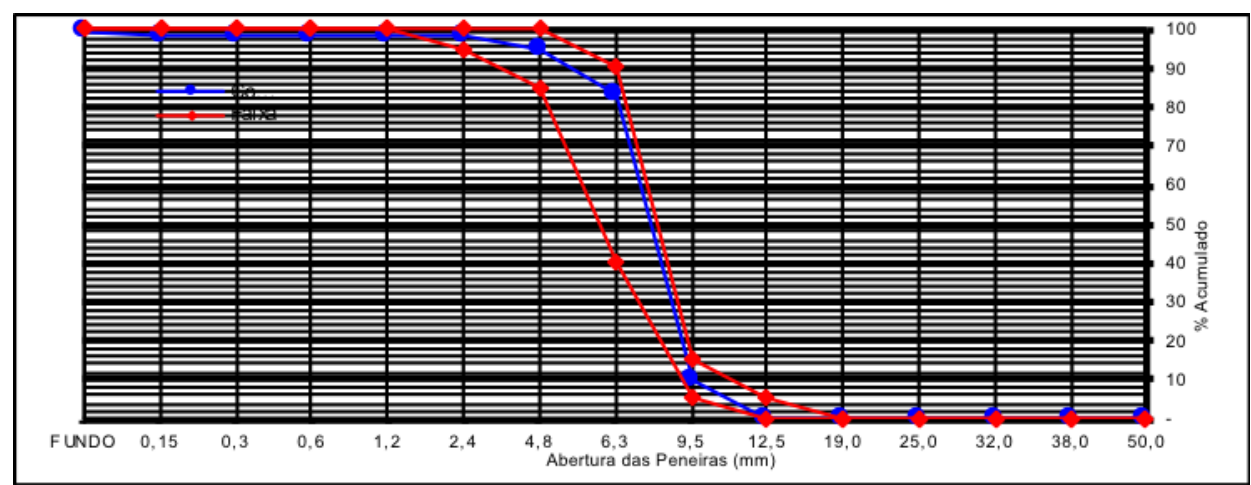

Figura 2 Composição granulométrica do agregado graúdo (Autor, 2019)

A Figura 2 mostra que o agregado graúdo utilizado está dentro do limite possuindo um diâmetro máximo de 19 mm. Ainda de acordo com o gráfico 1 pode-se observar que o agregado graúdo não possui valor de materiais finos passantes na peneira de $4,75 \mathrm{~mm}$ acima do sugerido para essa zona granulométrica.

\subsection{Pó de Vidro}

O vidro utilizado nesta pesquisa foi proveniente da coleta seletiva de garrafas do tipo long-neck. Sendo que este material foi escolhido devido a sua abundância e por não possuir uma destinação adequada, já que não se trata de um recipiente retornável. Foram coletadas 50 garrafas de vidro para atender a massa necessária para substituição, pensando no desperdício na fase preliminar, no rendimento do moinho e na separação na peneira 4,8mm. Após a coleta realizouse o processo de lavagem com água aquecida a $50^{\circ} \mathrm{C}$ para remoção dos rótulos e das impurezas presentes, para realização dos demais procedimentos. As garrafas foram quebradas artesanalmente com auxilio de um martelo adquirindo diferentes tamanhos de grão, os cacos foram postos no moinho de bolas durante 15 minutos para obtenção de um material granular, este processo se repetiu quatro vezes, pois o moinho não tinha capacidade de moer todo material em única vez, por isso repetimos, os processos de moagem foram realizados em moinho de bolas de aço de laboratório (modelo jarro 200x300mm DXC).

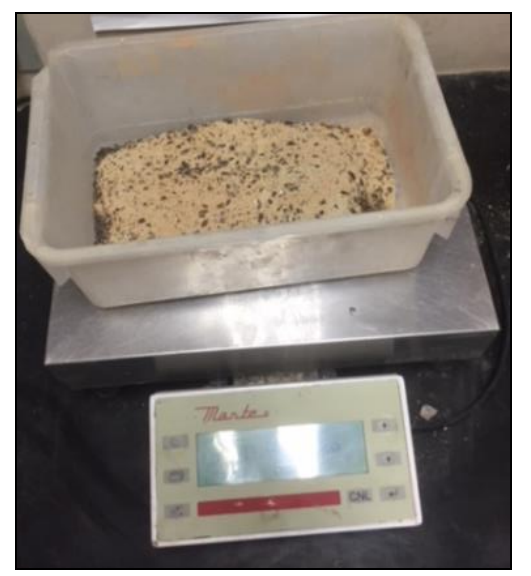

Figura 3 Vidro âmbar moído (Autor, 2019)

Os peneiramentos foram feitos por peneiras e agitador mecânico de laboratório de materiais de construção do CEULP/Ulbra. Para obtenção de uma curva granulométrica, segundo ABNT NM 248:2003, os cacos foram peneirados mecanicamente, sendo aproveitados os resíduos passantes na peneira ABNT4 (\# 4,8mm). Em relação à distribuição granulométrica do vidro moído, observa-se que as porcentagens retidas acumuladas nas diferentes peneiras estão dentro dos limites de distribuição granulométrica, previstos na ABNT 7211:2009, para que um material seja considerado agregado miúdo para concreto. 
Tabela 3 - Ensaios de caracterizados os agregado miúdo (Autor, 2019)

\begin{tabular}{l|c}
\hline \multicolumn{2}{c}{ Caracterização dos agregados } \\
\hline Massa unitária do agregado miúdo (NBR NM 45:2006) & $1,576 \mathrm{~g} / \mathrm{cm}^{3}$ \\
\hline Massa específica do agregado miúdo (NBR NM53:2009) & $2,464 \mathrm{~g} / \mathrm{cm}^{3}$ \\
\hline Teor de material pulverulento (NBR NM 46:2003) & $0,80 \%$ \\
\hline Módulo de finura da areia (NBR NM- 248:2003) & 2,2 \\
\hline Dimensão máxima característica (NBR NM- 248:2003) & $2,4 \mathrm{~mm}$ \\
\hline
\end{tabular}

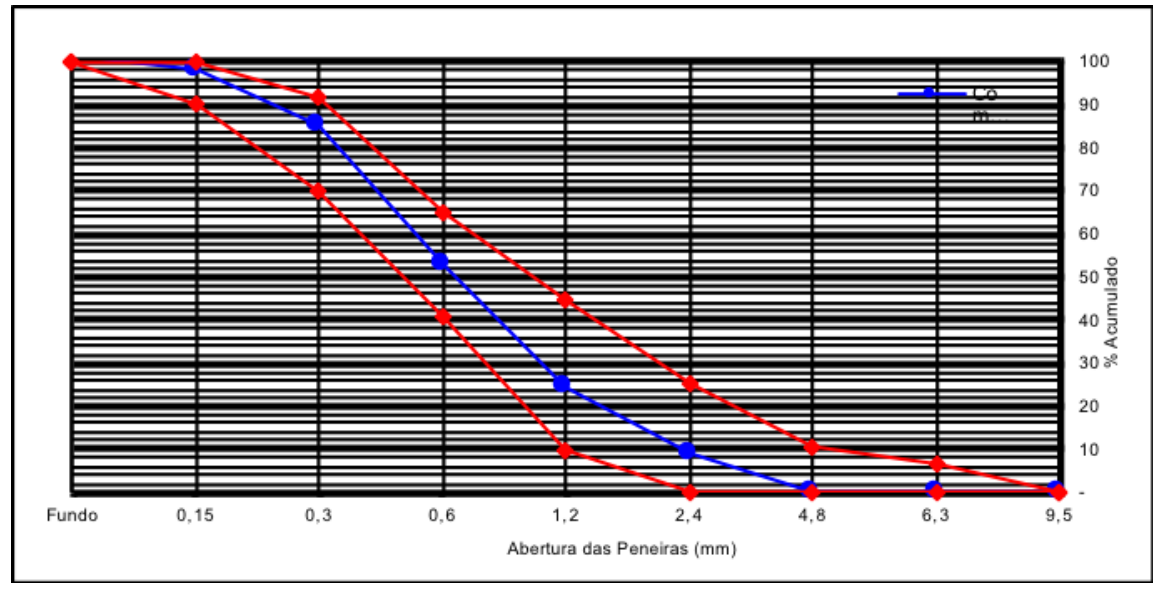

Figura 4 Composição granulométrica do pó de vidro (Autor, 2019).

\subsection{Dosagem dos Concretos}

A composição desenvolvida no presente trabalho foi dosada pelo método do ACI 211.1-91 (American Concrete Institute). Foi desenvolvido a composição referência definido como composição piloto, ou seja, 100\% de areia natural, para que, em seguida, se estabelecesse 3 novas composições: cada um com 3 teores distintos de substituição da areia natural pelo pó de vidro (10, 20 e 40\%). Dosou-se, então, um concreto com fck $=25 \mathrm{MPa}$ com abatimento de $100 \pm 20$ $\mathrm{mm}$.

Tabela 4 - Composições unitários para teores de substituição (Autor, 2019).
\begin{tabular}{c|c|c|c|c|c}
\hline \multicolumn{7}{c}{ Composições Unitários } \\
\hline Composição & Cimento & Areia & Pó de Vidro & Brita & a/c \\
\hline T0\% & 1 & 2,194 & - & 3,040 & 0,520 \\
\hline T10\% & 1 & 1,975 & 0,219 & 3,040 & 0,520 \\
\hline T20\% & 1 & 1,755 & 0,395 & 3,040 & 0,520 \\
\hline T40\% & 1 & 1,316 & 0,702 & 3,040 & 0,520 \\
\hline T0\% & 1 & 2,194 & - & 3,040 & 0,520 \\
\hline T10\% & 1 & 1,975 & 0,219 & 3,040 & 0,520 \\
\hline
\end{tabular}

Ainda que não faça parte do método de dosagem ACI 211.1-91, foi estipulado um teor de argamassa de 54\% através da composição piloto, para que o concreto apresentasse boas condições de trabalho e acabamento através de aferições visuais sugeridas pelo IPT-EPUSP.

\subsection{Concreto Fresco}

No estado fresco, foram comparados os abatimentos nos diferentes teores pelo ensaio do abatimento do tronco de cone (slump test), segundo ABNT NBR NM 67 (1998).

\subsection{Concreto Endurecido}

Após a dosagem, foram confecionados 3 corpos de prova (por idade) de dimensões $10 \mathrm{~cm}$ x $20 \mathrm{~cm}$ para realização do ensaio de resistência à compressão (ABNT NBR 5739 (1994)) e corpos de prova $15 \mathrm{~cm}$ x $30 \mathrm{~cm}$ para realização do 
ensaio de resistência à tração por compressão diametral (ABNT NBR 7222 (2011)). Também foi realizado o ensaio de absorção por imersão segundo ABNT NBR 9778 (2005).

\section{RESULTADOS}

\subsection{Concreto Fresco}

Segundo Metha \& Monteiro (2015) a fluidez inicial natural do concreto é uma de suas características mais importantes, pois permite que corpos resistentes sejam moldados com formas diversas, de maneira simples e custos relativamente baixos. Eles também apontam que a trabalhabilidade do concreto fresco determina o quão facilmente este material pode ser manipulado sem que haja segregação, portanto foi avaliada a influência da substituição do agregado miúdo pelo pó de vidro no abatimento do concreto, além das análises visuais para aferir se houve exsudação na pasta e segregações dos agregados.

Tabela 5 - Resultado do abatimento do tronco de cone (Autor, 2019).

\begin{tabular}{c|c}
\hline \multicolumn{2}{c}{ Slump Test ABNT NBR NM 67 (1998) } \\
\hline Composição & Abatimento \\
\hline T0\% & $95 \mathrm{~mm}$ \\
\hline $\mathrm{T} 10 \%$ & $100 \mathrm{~mm}$ \\
\hline $\mathrm{T} 20 \%$ & $120 \mathrm{~mm}$ \\
\hline $\mathrm{T} 40 \%$ & $130 \mathrm{~mm}$ \\
\hline
\end{tabular}

A Tabela 5 mostra que, na medida em que se aumentou o teor de pó de vidro, o abatimento também aumentou. Esse fator é decorrente das características vidro, pois, segundo Metha \& Monteiro (2015), a forma e textura dos agregados dos agregados são cruciais nas ligações entre a pasta e o agregado, ou seja, influenciam na trabalhabilidade e na compacidade. $\mathrm{O}$ agregado de vidro produzido na pesquisa apresenta forma arredondada em virtude do processo de moagem, porém a principal causa do ganho de abatimento seja a textura superficial do vidro que, segundo Dyer e Dhir (2001), do vidro é lisa e impermeável, esses fatores são, portanto, responsáveis pelo aumento do abatimento do concreto quanto maior o teor de vidro empregado.

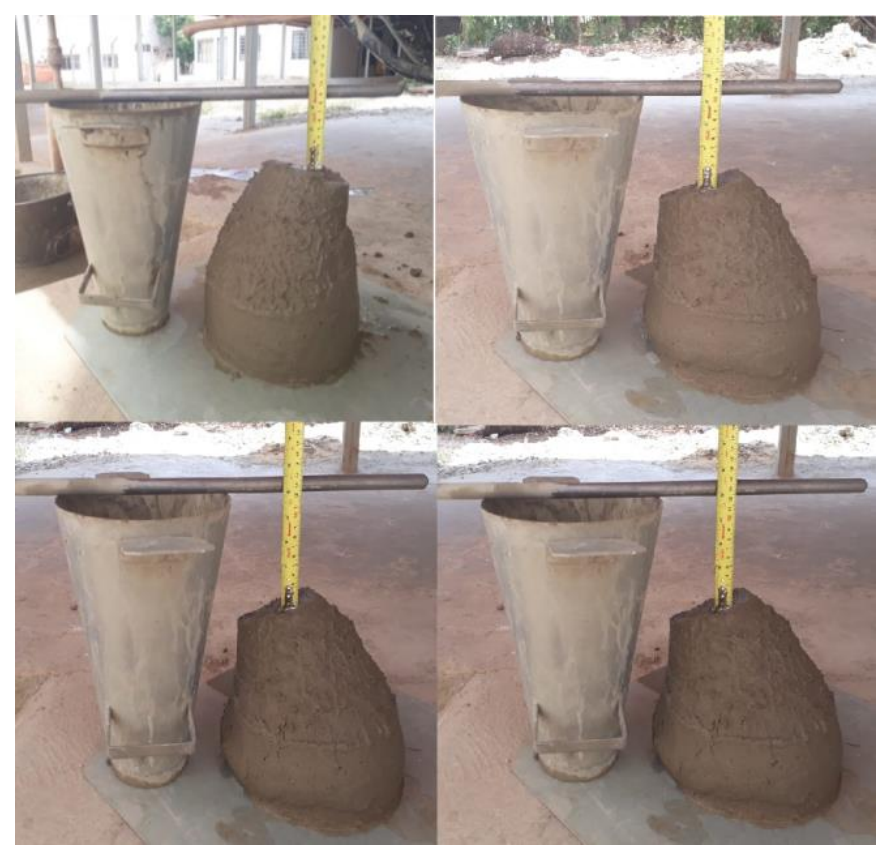

Figura 5 Aumento dos abatimentos com o aumento do teor de vidro (Autor, 2019)

As imagens mostram que, apesar do abatimento ter aumentado o concreto ainda se mostrou coeso e com condições de acabamento.

\subsection{Concreto no Estado Endurecido}


A resistência é a propriedade do material que traduz sua capacidade de conter esforços sem romper. Por vezes, detectase a ruptura no surgimento de fissuras neste material, porém o concreto pode apresentar microfissuras mesmo sem ter sido solicitado. Sendo assim, a resistência do concreto está ligada à tensão que causa sua ruptura (tensão máxima de ruptura) e está associada exclusivamente à relação água/cimento e do teor de ar incorporado. (METHA e MONTEIRO, 2015). A Tabela 6 abaixo apresenta os valores de resistência à compressão dos corpos de prova nas diferentes idades, bem como seu valor médio.

Tabela 6 -Resistência média à compressão (Autor, 2019).

\begin{tabular}{c|ccc}
\hline Composição & Idade (dias) & Resistência Média (Mpa) & Desvio padrão \\
\hline \multirow{3}{*}{ T0\% } & 7 & 23,65 & 0,26 \\
& 14 & 29,05 & 0,53 \\
& 28 & 33,55 & 0,09 \\
\hline \multirow{3}{*}{ T10\% } & 7 & 21,9 & 0,30 \\
& 14 & 26,25 & 0,55 \\
& 28 & 29,55 & 0,40 \\
\hline \multirow{2}{*}{ T20\% } & 7 & 21,1 & 0,13 \\
& 14 & 25,2 & 0,77 \\
& 28 & 27,25 & 0,30 \\
\hline \multirow{2}{*}{ T40\% } & 7 & 19,15 & 0,23 \\
& 14 & 22,3 & 0,38 \\
& 28 & 24,35 & 0,15 \\
\hline
\end{tabular}

Nota-se que houve uma perda de resistência aos 28 dias com o aumento do teor de substituição do agregado miúdo pelo pó de vidro. O gráfico abaixo ilustra essa diferença nas resistências à compressão.

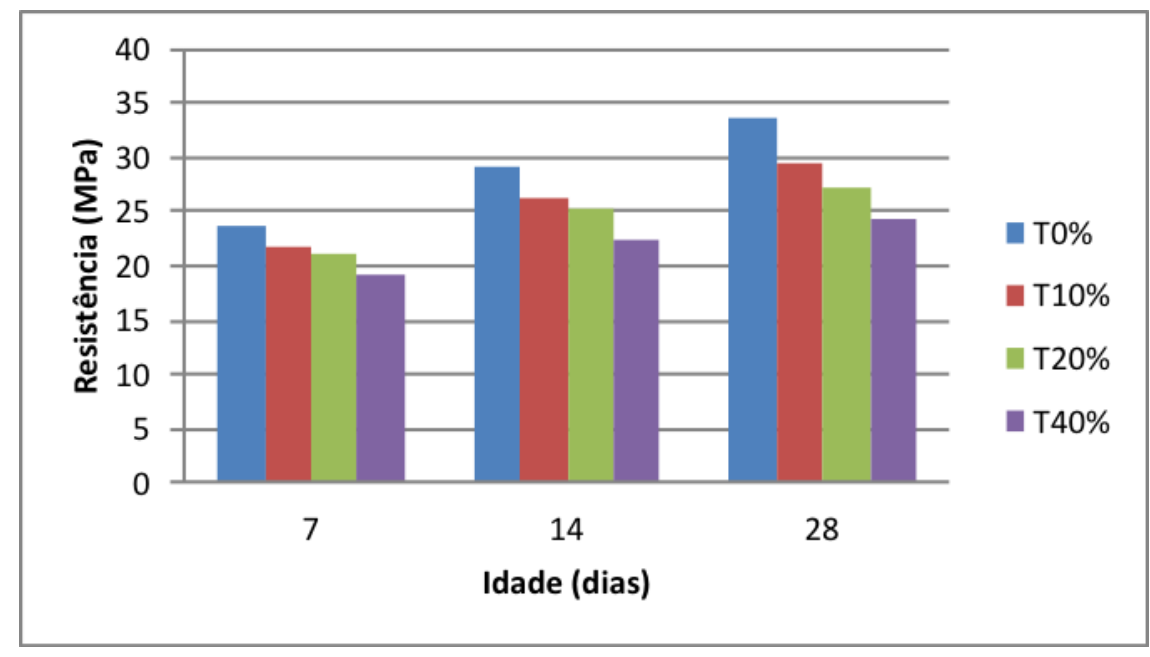

Figura 6 Resistência média à compressão ao longo do tempo (Autor, 2019).

Em relação à composição referência, as composições de 10, 20 e 40\% apresentaram uma redução de 11,92\%; 18,78\% e 27,42 \%, respectivamente. Essa diferença se dá também em virtude da forma e textura do agregado de vidro, pois, conforme ilustram Metha \& Monteiro (2015) em relação à forma e textura dos agregados, quanto mais rugosa for a superfície do agregado, maior é o intertravamento mecânico entre o agregado e a matriz de cimento.

Tabela 7 - Resultado da resistência à tração por compressão diametral (Autor, 2019).

\begin{tabular}{c|c|c|c}
\hline Composição & Idade (dias) & Resistência Média (Mpa) & Desvio padrão \\
\hline T0\% & 28 & 3,68 & 0,23 \\
\hline T10\% & 28 & 3,27 & 0,33 \\
\hline T20\% & 28 & 3,03 & 0,49 \\
\hline T40\% & 28 & 2,99 & 0,15 \\
\hline
\end{tabular}


Nota-se que, assim como na resistência à compressão, na tração também houve diminuição de resistência, como ilustrado no gráfico abaixo:

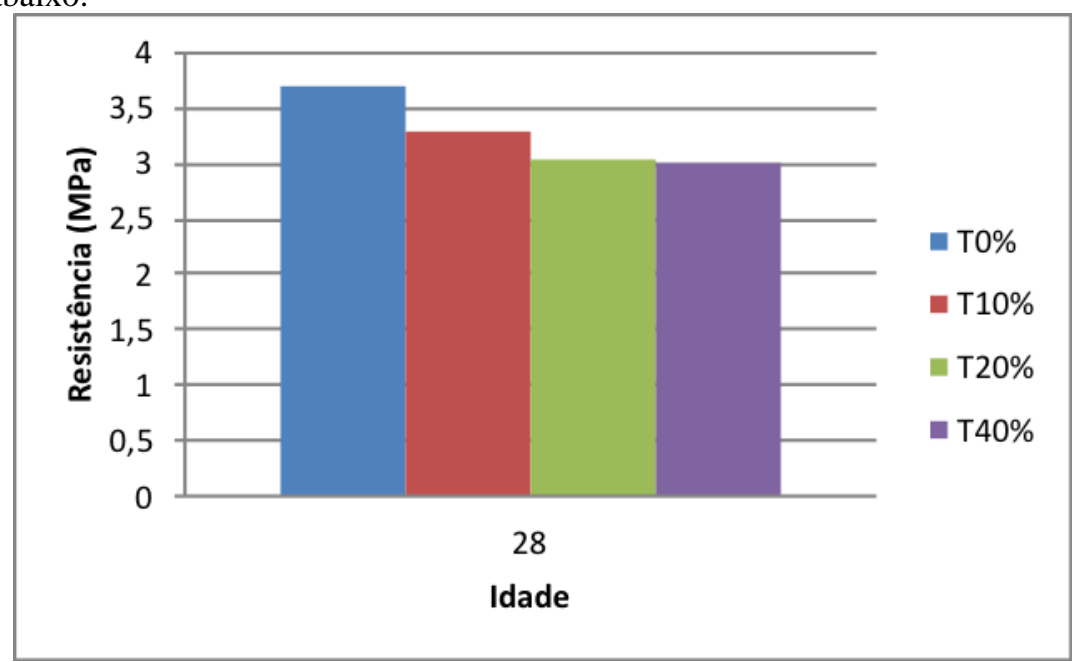

Figura 7 Resistência média à tração ao longo do tempo (Autor, 2019).

Essa redução também se justifica na textura superficial e forma dos grãos de vidro. As forças de ligação entre as partículas de vidro e a pasta são mais fracas se comparadas com a ligação da pasta com as partículas de agregados naturais. Logo, um aumento da massa de vidro no concreto aumenta a massa de agregado ligada mais fracamente à pasta.

A perda de resistência com o aumento dos teores de vidro no concreto refletiu no teor de absorção de água do concreto e em sua massa específica. Propriedade extremamente importante para a durabilidade do concreto, pois, segundo Medeiros, Andrade e Helene (2010) um concreto mais permeável facilita o ataque de agentes agressivos, caso os poros do concreto formem capilares. A Tabela 8 mostra os índices de absorção de água e massa específica para os diferentes teores de substituição, segundo ABNT NBR 9778 (2005).

Tabela 8 - Absorção de água e massa específica (Autor, 2019).

\begin{tabular}{c|c|c|c}
\hline Composição & $\begin{array}{c}\text { Absorção de } \\
\text { água (\%) }\end{array}$ & $\begin{array}{c}\text { Massa específica seca } \\
\mathrm{g} / \mathrm{cm}^{3}\end{array}$ & $\begin{array}{c}\text { Massa específica saturada } \\
\mathrm{g} / \mathrm{cm}^{3}\end{array}$ \\
\hline T0\% & 4,98 & 2,42 & 2,496 \\
\hline $\mathrm{T} 10 \%$ & 5,01 & 2,393 & 2,448 \\
\hline $\mathrm{T} 20 \%$ & 5,22 & 2,352 & 2,421 \\
\hline T40\% & 5,32 & 2,345 & 2,415 \\
\hline
\end{tabular}

Em relação à composição referência, a absorção de água das composições com 10\%, $20 \%$ e $40 \%$ de substituição variaram $0,03 \% ; 0,24 \% ; 0,34 \%$ respectivamente.

\section{CONCLUSÃO}

Diante dos resultados obtidos neste trabalho, conclui-se que uma substituição direta do agregado miúdo pelo pó de vidro não se apresentou como uma alternativa viável tecnicamente, pois, nenhuma das composições contendo o vidro apresentou resistência igual ou superior ao fcj da dosagem (31,5 MPa). Além disso, apesar das substituições terem gerado concretos mais leves, os teores de absorção aumentaram com o aumento do teor de vidro, o que pode comprometer a durabilidade do concreto, apesar desse acréscimo de absorção não ter sido significativo. Porém, em relação ao estado plástico, o concreto apresenta propriedades satisfatórias com relação à trabalhabilidade, o que pode trazer benefícios no quesito durabilidade, ou seja, reduzindo a quantidade de água na mistura, consequentemente reduzindo a porosidade do concreto. Portanto, caso seja feito um novo estudo de dosagem com adição de novos recursos, tais como aditivos superplastificates, sílica ativa, outras adições minerais ou ainda, utilizar o vidro em granulometrias menores, de tal maneira que possa se obter um efeito filler deste resíduo, pode ser possível que se obtenha concretos com esse agregado reciclado, trazendo uma viabilidade técnica e ambiental. Outra sugestão para trabalhos futuros é o estudo para concretos com idades mais avançadas a fim de se observar a durabilidade e se possa haver acréscimos em resistência. 


\section{REFERÊNCIAS}

ABNT. NM 33: Concreto: Amostragem de concreto fresco. Rio de Janeiro, 1998

ABNT. NBR 12653: Materiais Pozolânicos. Rio de Janeiro, 1992

ARAUJO, J, G. Influencia de adições minerais pozolânicas e de finos de pedreiras nas propriedades mecânicas e na micro estrutura de concreto auto adensavel.2007.86p.Dissertação(Mestrado em Engenharia Civil) Universidade Federal de Goias, 2007.

Compromisso Empresarial Para Reciclagem (CEMPRE):<http://cempre.org.br/artigo-publicacao/fichatecnica/id/6/vidro > acesso em: novembro, 2018.

C. Polley, S.M. Cramer, R.V. de la Cruz, Potential for using wasteglass in Portland cement concrete, J Materials in Civil Engineering,ASCE 10 (4) (1998) 210-219.

Dyer, T.D., Dhir, R.K., 2001. Chemical reactions of glass cullet used as a cement component, ASCE Journal of Materials in Civil Engineering, 2001, pp412-417.

FERNANDES, C. A., et al.. Reforço de pilares de elevado do metrô de São Paulo, 41* Congresso Brasileiro do Concreto. São Paulo, IBRACON, 1999.

GOUVEIA, N. Residuos solidos urbanos: impactos socioambientais e perspectiva de manejo sustentável com inclusao social. Ciência \& Saúde Coletiva, Sao Paulo, 2012, 17(6):1503-1510.

HELENE, Paulo R. L.; ANDRADE, Nome. Materiais de construção civil e princípios de ciência e engenharia de materiais. ed. G.C. Isaia. 2 ed. São Paulo: IBRACON, 2010.

IBRACON (instituto Brasileiro de Concreto). GERALDO CECHELLA ISAIA (São Paulo). (Ed.). Concreto: Ciência e Tecnologia. São Paulo: Ipsis Gráfica e Editora, 2011. 931 p.

Ismail, Zainab Z; Al-Hashmi, Enas A. Recycling of Waste Glass as A Partial Replacement for Fine Aggregate in Concrete. October, 2008.

SILVA, José Glêdson de Sousa. Produção de concreto cimentício com agregado de resíduos de vidro plano temperado. 2015. 158 f. Tese (Doutorado) - Curso de Programa de Pós-graduaÇÃo em Ciência e Engenharia de Materiais, Centro de Ciências e Tecnologia, Universidade Federal de Campina Grande, Campina Grande, 2015.

LOPEZ, D. A. R; AZEVEDO, C. A. P. de and BARBOSA NETO, E.. Avaliação das propriedades físicas e mecânicas de concretos produzidos com vidro cominuído como agregado fino. Cerâmica [online]. 2005, vol.51, n.320, pp.318-324. ISSN 0366-6913. http://dx.doi.org/10.1590/S0366-69132005000400003.

MEDEIROS, Marcelo H. F. ; ANDRADE, J. J. O. ; HELENE, Paulo . Durabilidade e Vida Útil das Estruturas de Concreto. In: Geraldo Isaia. (Org.). Concreto: Ciência e Tecnologia. 1 ed. São Paulo: Ibracon, 2011, v. 1, p. 773-808.

MEHTA, P. Kumar; MONTEIRO, J. M. Paulo. Concreto: microestrutura, propriedades e materiais. 2 ed. São Paulo: IBRACON,2014.

SHACKELFORD,J.E.Ciência dos materiais.SãoPaulo:Prentice Hall, 2008. 